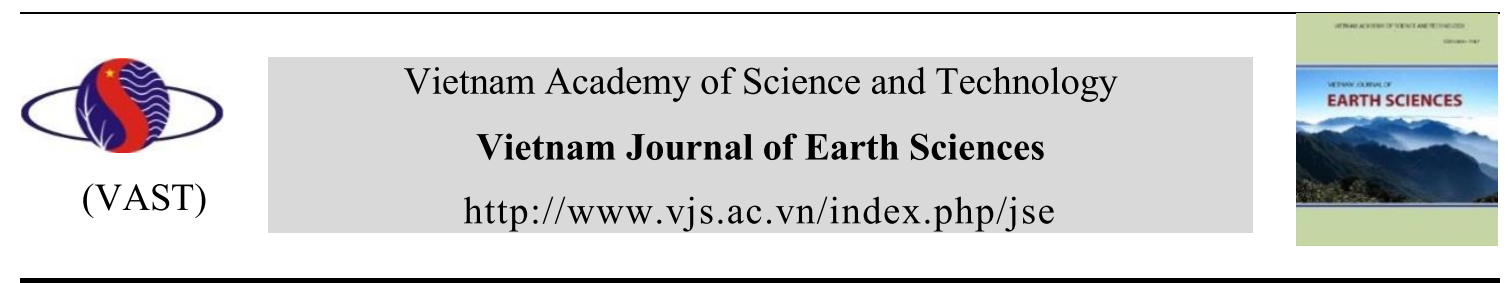

\title{
Desorption and re-adsorption of PAHS on aircraft soot surface
}

\author{
Nguyen Mai Lan \\ Faculty of Environment, Hanoi University of Natural Resources and Environment
}

Received 11 November 2019; Received in revised form 14 July 2020; Accepted 20 August 2020

\begin{abstract}
Polycyclic Aromatic Hydrocarbons (PAHs) in aircraft soot are capable to distribute in the gas phase and particulate phase in chemical transformations in the atmosphere. The desorption of PAHs from the soot surface is a preliminary step in the study of the reactivity of particulate PAHs. The desorption kinetics of PAHs are measured from soot samples to determine desorption rate constants for different PAHs as a function of temperature and the binding energies between PAHs and soot. The kinetics of degradation of particulate PAHs were studied in the flow reactor. The soot samples previously deposited on a Pyrex tube are introduced into the reactor along its axis and the concentrations of PAHs adsorbed on soot are determined by the High-Performance Liquid Chromatography (HPLC) as a function of the desorption time. The results show a correlation between the size of PAHs and the thermodynamics of desorption: with the PAHs have the same number of carbon atoms, their energies of desorption are very similar and increase with this number. The activation energies EA and the number of carbon atoms in PAHs have a linear correlation. It is consistent with the additivity of the laws Van der Waals. The similarity between the activation energies of desorption of PAHs and the corresponding sublimation enthalpies is consistent with the similarity between the graphitic structure of soot and the structure of PAHs.
\end{abstract}

Keywords: Desorption; re-adsorption; PAHs, aircraft; soot; reactor; HPLC.

C2020 Vietnam Academy of Science and Technology

\section{Introduction}

Nowadays, the aviation industry has been growing at a rapid pace in recent years. According to a report of the Air Transport Action Group (ATAG) (Aviation Benefits beyond borders, 2018, Meng et al., 2018), about 41.9 million commercial flights were scheduled in the world in 2017, up $15.06 \%$ compared to 2013. There are about 1,303 commercial airlines and 31.717 commercial aircraft in service and about 114795 flights per day on average. In 2018, Vietnam's

*Corresponding author, Email: mi_lan1981@yahoo.com airlines served nearly 50 million passengers, up $10.1 \%$ year-on-year, and transported 400,000 tons of goods, up $27.2 \%$. The aviation industry of Vietnam grows $14-15 \%$ per year, equivalent to the GDP growth rate of $6.8-7 \%$.

The world's airline paid \$ 149 billion for 341 billion liters of jet fuel in 2017 and was responsible for $2 \%$ of $\mathrm{CO}_{2}$ emissions of global human emissions. Besides causing global warming by $\mathrm{CO}_{2}$, aircraft emissions of sulfates and soot particles also affect climate. Direct sulfate emissions cause cooling because of reflecting sunlight. While direct soot emissions have a warming effect because 
the black carbon or dark soot particles tend to absorb solar radiation. They also decrease albedo when deposited over snow. The direct effect of particles from aircraft is well understood as a small effect while the indirect effects, however, are poorly understood.

The soot particles are not composed solely of elemental carbon. They also contain a more or less significant fraction of organic material adsorbed during the cooling of the products of combustion. It is therefore difficult to completely dissociate elemental carbon from organic carbon. In addition, the soot formation mechanism involves another class of compounds: Polycyclic Aromatic Hydrocarbons (PAHs) which would be precursors of these particles.

PAHs are dispersed in the atmosphere in gaseous or particulate form depending on their saturated vapor pressure. This distribution between the two phases is a function of the molecular weight of the compound, its vapor pressure and ambient temperature (compounds with two benzene rings are mainly found in the gas phase, those with four rings in the particulate phase, PAHs with three nuclei which may be in the gas or particulate phase). This distribution of PAHs requires a sampling method adapted to the two phases simultaneously. PAHs can react with UV rays, nitrogen oxides, ozone, sulfur compounds, peroxy radicals, or other free radicals, and decompose thermally.

These studies aim to determine the distribution of PAHs between the gas phase and particulate phase and to characterize their chemical transformations in the atmosphere. Soot has been chosen as a substrate, is one of the products of the incomplete combustion from fossil fuels and biomass, it contains high levels of PAHs and is a very important source of these compounds in the atmosphere.

\section{Methods}

All experimental work is carried out in the laboratory of ICARE (CNRS), France.

\subsection{Soot production by premixed flame}

A hydrocarbon mixture (decane/ propylbenzene/propyl cyclohexane: 74/15/11) was used as fuel in the present study, represents the combustion of kerosene in the airplane (Dagaut, 2002). On the other hand, it facilitates the preparation of soot due to a limited number of hydrocarbons (with lower boiling points) compared to kerosene.

We used a flat flame burner in the preparation and deposition of soot samples from pre-mixed flames of liquid fuels in a reproducible manner and under wellcontrolled combustion conditions. The soot is deposited on a Pyrex tube of $0.9 \mathrm{~cm}$ external diameter before being introduced into the flow reactor. For this, the tube is moved horizontally in the flame centimeter by centimeter with a time step set by the user. The thickness of soot deposited on the tube is proportional to the passage time in the flame. The deposit of soot is assured homogeneous. The distribution of PAHs over the entire soot sample length is homogeneous and reproducible. Specific (BET) surface area and bulk density of the soot samples prepared and collected in this way were determined in previous studies from our group (Lelièvre, 2004; Bedjanian, 2005; Cong et al., 2013) $120 \pm 20 \mathrm{~m}^{2} \mathrm{~g}^{-1}$ and $(3.6 \pm 0.7) \times 10^{-2} \mathrm{~g} \mathrm{~cm}^{-3}$, respectively.

\subsection{Soot deposition in a flow reactor}

The tube on which the soot is deposited is introduced into a flow reactor to study the kinetics of desorption. The main reactor consists of a fixed pyrex cylindrical tube with a length of $45 \mathrm{~cm}$ and an internal diameter of $2.4 \mathrm{~cm}$. The main reactor is provided with a double outer wall where fluid (water or ethanol) can circulate in order to regulate the temperature of the main reactor. A coaxial configuration of the flow reactor with a removable triple central injector was used for the desorption experiments: the pyrex tube 
where soot is deposed, is introduced into the reactor along its axis. This tube is surrounded by another tube in order to protect the soot. The third tube of the injector allows the circulation of the thermostatic liquid inside the first tube. Experiments were specifically carried out in Lelièvre, 2004; Bedjanian, 2005 and Lelièvre, 2004. This makes it possible to maintain the temperature in the same level in the main reactor and on the soot surface during measurements of the desorption rate of PAHs.

\subsection{Soot analyzing by High Performance Liquid Chromatography (HPLC) and Mass Spectrometry (MS)}

Fresh soot samples were used in all kinetic experiments. The chemical stability of the samples, or more specifically, the absence of significant changes in the concentration of PAHs of the soot sample between its preparation and its introduction into the reactor (10-20 minutes) was verified in specific experiences. For this, the evolution of the concentrations of particulate PAHs was monitored as a function of the residence time of samples under laboratory conditions ( $\mathrm{T}=(298 \pm 3) \mathrm{K}, \mathrm{P}=760$ Torr). It has been observed that the concentration of PAHs at the surface does not change during the first hour of sample storage (even for the lightest compounds such as phenanthrene and anthracene).

Rate constants of the soot surface desorption were measured by adsorbed PAH concentrations at the soot surface as a function of the desorption time corresponding to the residence time in the reactor at a given temperature. Two methods of analysis were used to study the desorption kinetics of particulate PAHs. The HPLC method (off-line method) was used in most experiments to measure the PAH concentrations present in the soot sample extraction solvent at different desorption times. The other method, mass spectrometry (in situ detection) made it possible to directly measure, in the gaseous phase, the PAH concentrations desorbed from the soot surface. Kinetics of soot-bound PAHs desorption was studied in a flow reactor combined with a modulated molecular beam mass spectrometer for detection of gaseous species (Lelièvre, 2004; Bedjanian, 2005; Lelièvre, 2004).

\section{Results}

\subsection{Desorption kinetics}

Examples of desorption kinetics in the flow reactor measured by HPLC for fluoranthene and anthracene at $\mathrm{T}=300 \mathrm{~K}$ are shown in Fig. 1. We observed that the kinetics of PAHs reach a plateau. It means that some of the adsorbed PAHs remain on the soot surface and are not released into the gas phase even after a relatively long residence time in the reactor $(\approx 17$ hours).

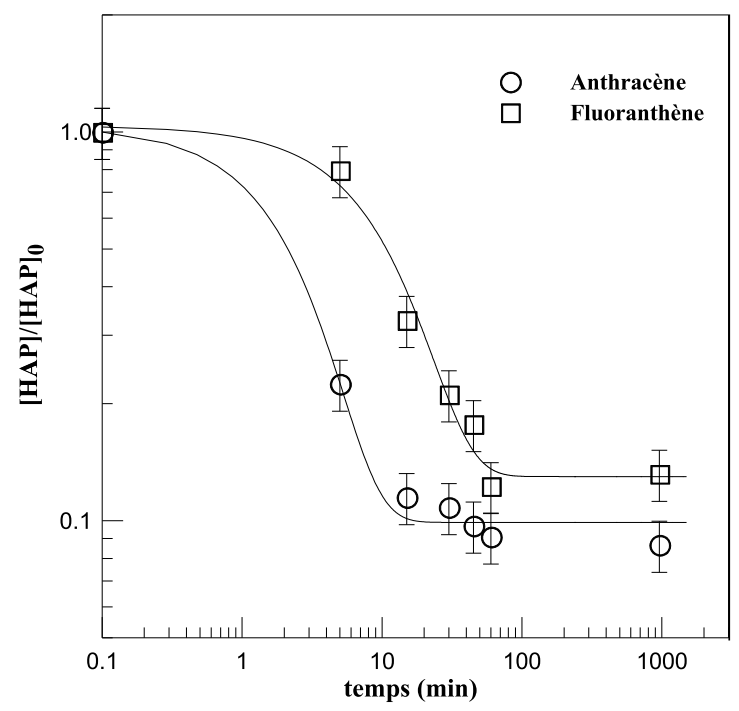

Figure 1. PAH desorption kinetics of soot in a long resident time at $\mathrm{T}=300 \mathrm{~K}, \mathrm{P} \leq 0.1$ Torr

The number of PAH molecules remaining on the surface depends on the temperature of the soot sample. As might be expected, the plateau level drops with increasing temperature, as shown in Fig. 2 for pyrene. 
This phenomenon of partial desorption of PAHs from the soot surface is probably due to the trapping of PAHs in the micropores: diffusion delayed by a re-adsorption leading to a local adsorption/desorption balance in the soot volume.

In our PAH desorption study, the plateau region (un-desorbed molecules) was not considered for determination of desorption rate constants. For measurement of low desorption rates, the first-order kinetics are used to describe reasonably experimental data. The first order velocity coefficients obtained from the exponential simulation are as follow:

$$
[\mathrm{PAH}]=[\mathrm{PAH}]_{0} \times \mathrm{e}^{-\mathrm{k}} \mathrm{des}^{\mathrm{t}}
$$

$\mathrm{k}_{\mathrm{des}}$ : desorption rate constant

When plateau exists, the kinetics were simulated with the following exponential function:

$$
\underset{\times \mathrm{e}^{\mathrm{k}}{ }_{\text {des }}^{\mathrm{t}}}{[\mathrm{PAH}]}=[\mathrm{PAH}]_{\text {plateau }}+\left([\mathrm{PAH}]_{0}-[\mathrm{PAH}]_{\text {plateau }}\right)
$$

$[\mathrm{PAH}]_{0}$ : initial concentration of PAH

$[\mathrm{PAH}]_{\text {plateau }}$ : concentration of $\mathrm{PAH}$ in region of plateau

As a result, the non-desorbed molecules were not considered for the determination of first-order rate constants.

The second approach used for kinetic measurements consisted of a mass spectrometric detection of species desorbed from the soot surface in the reactor. An example shown in Fig. 3 shows typical behavior of the mass spectral signal intensity at $\mathrm{m} / \mathrm{z}=202$ (pyrene + fluoranthene) when the soot sample is introduced at $t=0$ in the flow reactor. A decrease in the desorption rate because of the particulate PAHs concentration reduction caused a quickly initial desorption of PAHs.

The calculation of the PAH molecules desorbed from the soot surface, $\Delta[\mathrm{PAH}]$ is showed by the integration of the curve in a given time interval (Fig. 4). We obtain an exponential decay of particulate PAHs as follow :
$\Delta\left[[\mathrm{PAH}]=[\mathrm{PAH}]_{0}-[\mathrm{PAH}]=[\mathrm{PAH}]_{0} \times(1-\right.$ $\exp \left(-\mathrm{k}_{\mathrm{des}} \times \mathrm{t}\right)$

$[\mathrm{PAH}]_{0}$ : concentration of HAP in $\mathrm{t}=0$

$[\mathrm{PAH}]$ : concentration of HAp in $\mathrm{t}=\mathrm{t}$

The desorption rate constant $k_{\text {des }}$ is calculated by the simulation of the experimental points (Fig. 4) according to equation (3).

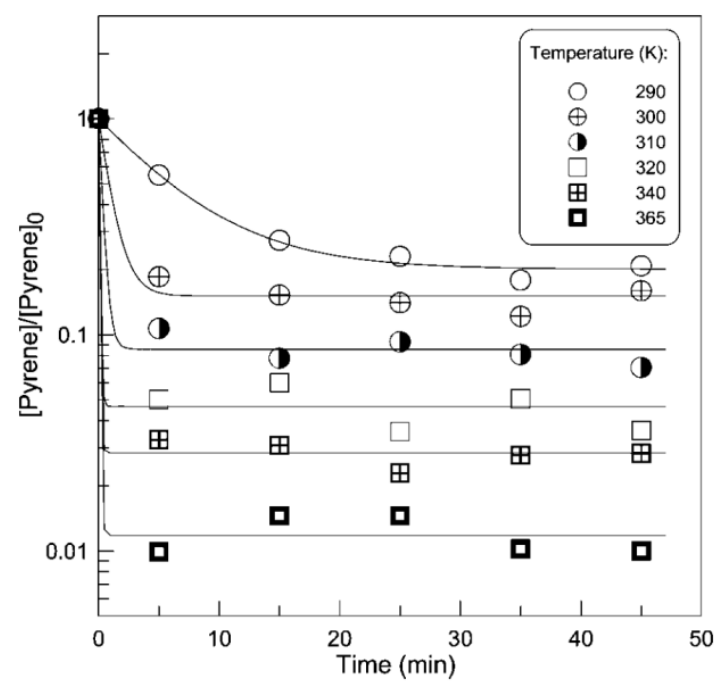

Figure 2. Desorption kinetics of Pyrene on soot surface with a plateau level as a function of temperature

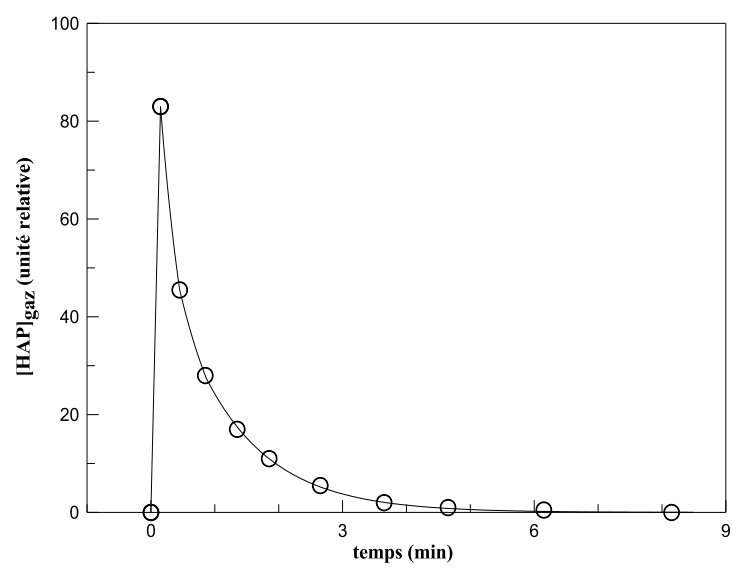

Figure 3. Concentration of fluoranthene and pyrene in gaseous phase desorbed from soot surrface in a function of time at $\mathrm{T}=310 \mathrm{~K}$, $\mathrm{P}=1$ Torr, flow velocity $=3000 \mathrm{~cm} / \mathrm{s}$, mass of soot $=1.3 \mathrm{mg}$, legth of soot sample $=14.2 \mathrm{~cm}$ 


\subsection{Re-adsorption of PAHs on the soot surface}

In the flow reactor, the PAH molecules desorbed from the soot surface can be re-adsorbed on the soot. The rate of re-adsorption can be estimated by:

$$
V_{\text {ads }}=k_{\text {ads }} \times(1-\theta) \times[\mathrm{HAP}]_{\mathrm{gaz}}
$$

$k_{\text {ads }}$ : adsorption rate constant,

$\theta=[\mathrm{PAH}] /[\mathrm{PAH}]_{0}$ : surface coverage ratio by PAHs.

To reduce the rate of re-adsorption, it is necessary to reduce the concentration of PAHs in the gas phase. There are two possibilities for this. Firstly, desorbed PAH is simply diluted with a carrier gas to increase the flow rate. Secondly, the ejected PAH molecules from the soot surface in the gas phase is reduced by decreasing the initial total number of PAH molecules introduced into the reactor, which is equivalent to a reduction of the total soot mass (by reducing the length of the soot sample and/or its thickness).

To study the effect of the re-adsorption of PAHs on soot, we measured desorption rate constant as a function of the flow velocity in the reactor for different masses of soot. Direct mass spectrometric detection of $\mathrm{m} / \mathrm{z}=202$ signal corresponding to the desorbed pyrene and fluoranthene molecules was performed in these experiments. All values of $k_{\text {des }}$ obtained are shown in Fig. 5 as a function of an empirical parameter (a ratio of the flow velocity $\left(\mathrm{cm} \mathrm{s}^{-1}\right)$ to the soot mass $\left.(\mathrm{mg})\right)$. In the data in Fig. 5, $\mathrm{k}_{\text {des }}$ can be considered independent of the ratios of flow velocities/soot mass for these ratios greater than $6000 \mathrm{~cm} \mathrm{~s}^{-1} \mathrm{mg}^{-1}$. It means that under these conditions the PAH re-adsorption processes can be neglected.

Consequently, the value of $k_{\text {des }}$ is measured in using the samples of soot with a mass of less than $0.5 \mathrm{mg}$ and a flow rate of $3000 \mathrm{~cm} . \mathrm{s}^{1}$ in the reactor. In this study, the desorption rates of PAHs were measured at a flow rate in the range of 3000 to $4300 \mathrm{~cm} \mathrm{~s}^{-1}$ and a total soot mass of 0.2 to $0.4 \mathrm{mg}$.

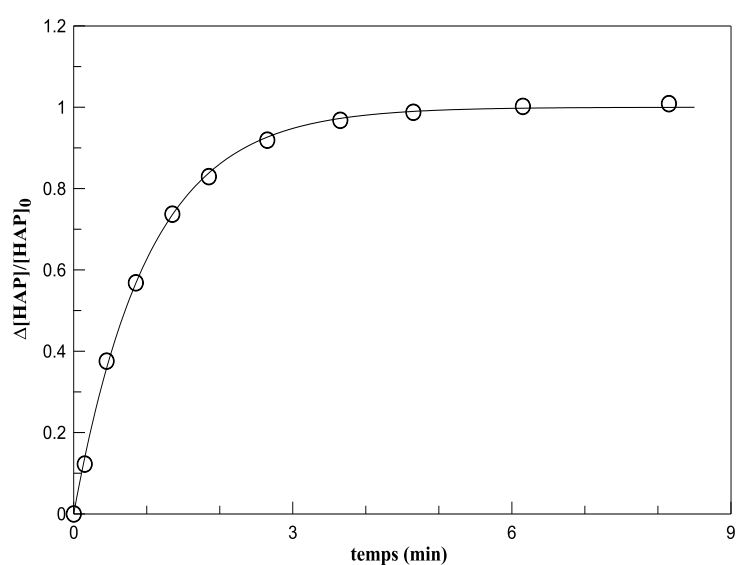

Figure 4. Fraction of fluoranthène + pyrène desorbed from soot surface in function of time

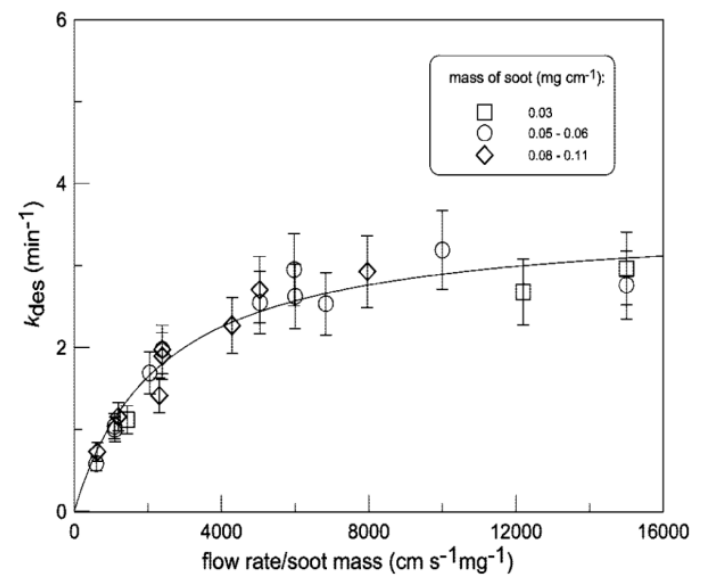

Figure 5. Desorption rates of fluoranthene + pyrene at $\mathrm{T}=310 \mathrm{~K}$. The error bars represent the $15 \%$ uncertainty on $\mathrm{k}_{\mathrm{des}} . \mathrm{o}-\mathrm{v}=3000 \mathrm{~cm} / \mathrm{s}, \mathrm{m}=$ $0,2-1,3 \mathrm{mg} ; \square-\mathrm{v}=(360-3980) \mathrm{cm} / \mathrm{s}, \mathrm{m}=0,6 \mathrm{mg}$

Figure 5 showed measured $\mathrm{k}_{\mathrm{des}}$ at a total pressure of 0.2-1.0 Torr of helium in the reactor and soot samples lengths in range of $2.7-14.9 \mathrm{~cm}$ and thicknesses of $0.03-0.11 \mathrm{mg}$ of soot per $\mathrm{cm}$ of deposit. Desorption rates were found independent of these parameters in our experimental conditions. The PAH desorption kinetics are independent of the soot thickness is an important point. It indicates that the diffusion of PAHs from the lower soot layers is not a limiting factor in the measurements of the desorption rates of the PAH in our experimental conditions. 
Figure 5 presented an estimation of the capture coefficient $(\gamma)$ of PAHs by the soot surface. The desorbed molecule would either be re-adsorbed on the soot surface $\left(\mathrm{k}_{\mathrm{ads}}\right)$ or evacuated from the reaction zone (determined by the soot sample length, L) by the flow of the carrier gas (flow velocity v), the measured desorption rate can be expressed by the equation:

$$
k_{d e s}^{m e s}=k d e s \times\left(1-\frac{k a d s}{k a d s+2 v / L}\right)
$$

where $\mathrm{L} / 2 \mathrm{v}$ is an average residence time of the PAHs. And $k_{a d s}$ is related to $\gamma$ by the expression:

$$
k a d s=\frac{\omega \gamma}{4} \frac{S}{V}
$$

where $\omega$ is the average molecular speed, $\mathrm{V}$ is the volume of the reaction zone, and $\mathrm{S}$ is the surface of the soot sample.

With $\mathrm{V}=3.8 \mathrm{~cm}^{2} \times \mathrm{L}$ (area of the section between the soot sample and the main reactor multiplied by the length of the sample), $\mathrm{S}=1200 \mathrm{~cm}^{2} \mathrm{mg}^{-1} \times \mathrm{m}$ (BET specific surface area of soot sample and soot mass in $\mathrm{mg}$ ) and $\omega=11922 \mathrm{~cm} \mathrm{~s}^{-1}$, we obtain: kads $=9.4 \times 10^{5}$ $\times \gamma \times \mathrm{m} / \mathrm{L}$, and

$$
k_{\text {des }}^{\text {mes }}=k_{\text {des }} \times\left(1-\frac{\gamma}{\gamma+2,1 \times 10^{-6} v / m}\right)
$$

The expression (7) (solid line in Fig. 5) provides a value of $\gamma \approx 0.005$ for the combined capture coefficient of fluoranthene and pyrene on the soot surface at $\mathrm{T}=310 \mathrm{~K}$.

\subsection{Kinetics of desorption as a function of temperature}

An example of $\mathrm{B}(\mathrm{a}) \mathrm{P}$ desorption kinetics from the soot surface at different temperatures in the range (315-350 K) is shown in Fig. 6.

The simulation of the experimental data with the exponential functions (equations (1) and (2)) is represented by the solid lines. From these curves, the desorption rate constant $\left(\mathrm{k}_{\mathrm{des}}\right)$ is calculated as a function of temperature. The experimental uncertainty is estimated at $15-25 \%$.

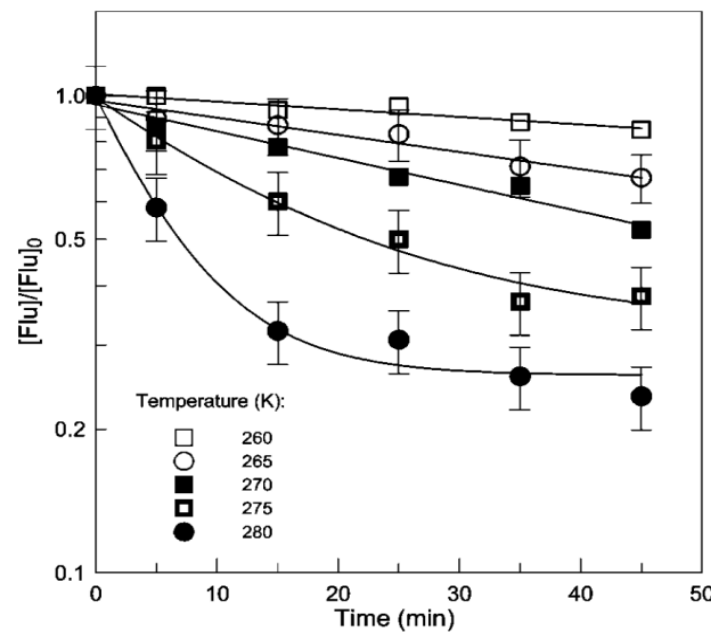

Figure 6. B(a)P desorption kinetics at different temperatures

Another example of desorption kinetics measured at a fixed temperature $(\mathrm{T}=325 \mathrm{~K})$ with different compounds in the reactor is shown in Fig. 7. It is found that the heavier the HAP molecule, the lower its desorption rate.

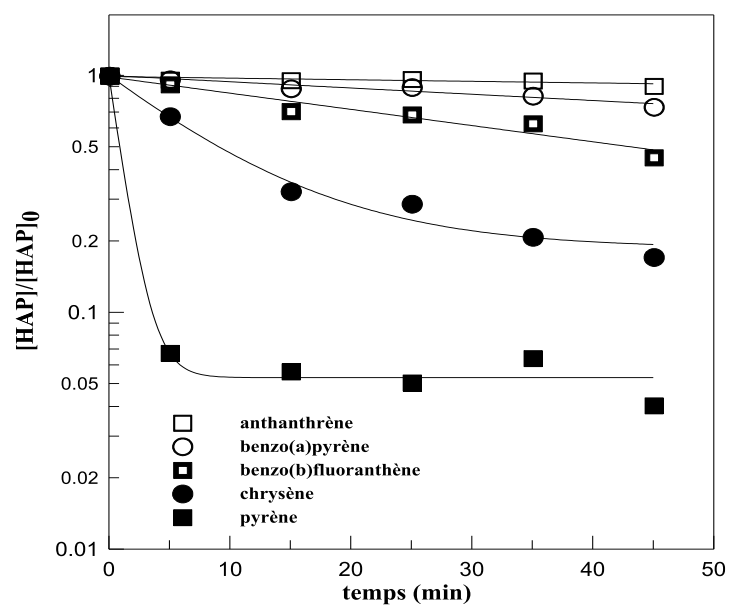

Figure 7. Desorption kinetics of different PAHs

$$
\text { at } \mathrm{T}=325 \mathrm{~K}
$$

The rate of desorption as a function of temperature is described by the Arrhenius equation:

$$
\mathrm{k}_{\mathrm{des}}=\mathrm{k}_{0} \times \exp \left(-\mathrm{E}_{\mathrm{A}} / \mathrm{RT}\right)
$$

where $\mathrm{k}_{0}$ : pre-exponential factor $\left(\mathrm{s}^{-1}\right)$

$E_{A}$ : activation energy for desorption $\left(\mathrm{J} \mathrm{mol}^{-1}\right)$ 
$\mathrm{R}$ : ideal gas constant $\left(\mathrm{J} \mathrm{K}^{-1} \mathrm{~mol}^{-1}\right)$

$\mathrm{T}$ : desorption temperature $(\mathrm{K})$

Figures 8, 9 show the temperature dependence of the desorption rate constants measured for different PAHs. A very good agreement between the obtained $\mathrm{k}_{\mathrm{des}}$ by two methods of measuring is shown in Fig. 8: the detection by mass spectrometry (relatively fast desorption) and analyzes by HPLC (slow desorption).

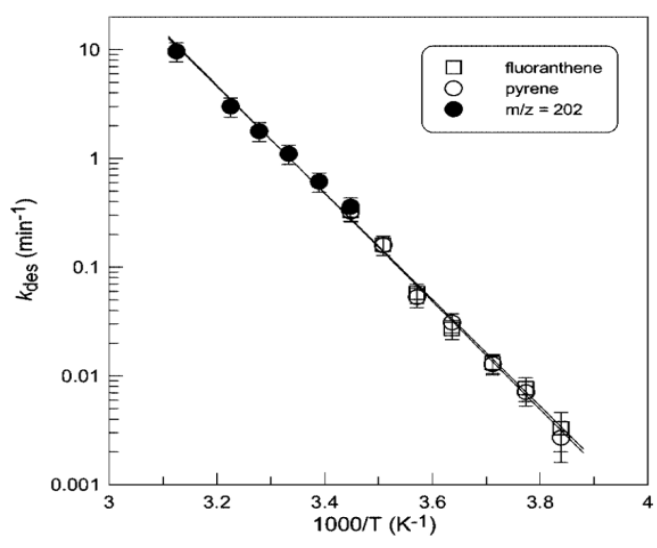

Figure $8 . \mathrm{k}_{\mathrm{des}}$ of pyrene and fluoranthene

- measured by spectrometry at $\mathrm{m} / \mathrm{z}=202$; $\square$, ,- measured by HPLC

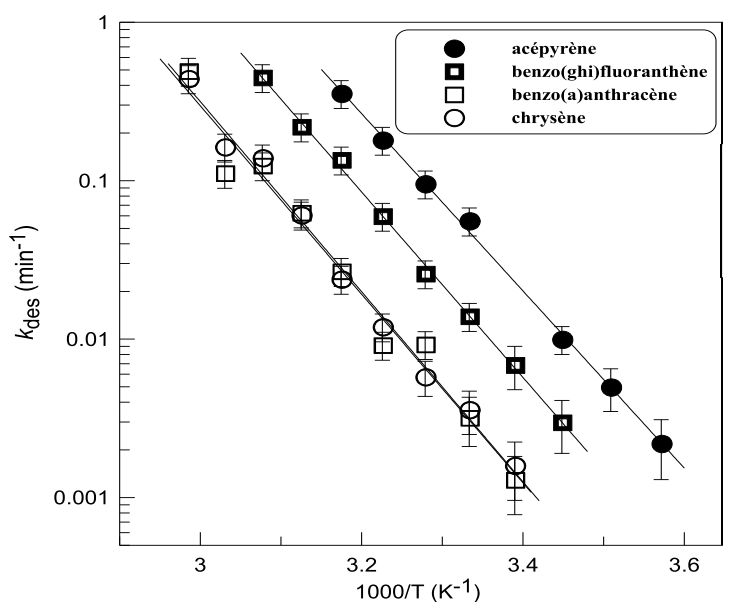

Figure 9. $\mathrm{k}_{\mathrm{des}}$ measured by HPLC of PAHs with mass $=226-228$ uma

The Arrhenius parameters obtained for the desorption of studied compounds are presented in Table 1. It may be noted that the temperature range of the $\mathrm{k}_{\mathrm{des}}$ measurements is different with the different compounds. It means that the values of $k_{\text {des }}$ must be measurable at the considered temperatures under the experimental conditions (observation time of the desorption kinetics in range of a few minutes to an hour).

\section{Discussion in atmospheric application}

A correlation between the size of PAHs and the thermodynamics of desorption is shown in Table 1. It is similar of the desorption energies (or binding energies for thermal desorption) of PAHs which have the same number of carbon atoms. The desorption energy also increase with this number number of carbon atoms.

Available literature data on desorption of PAHs from carbonaceous surfaces are consistent with our results such as Steiner and Burtscher (1994), Zacharia et al. (2004), Aubin and Abbatt, 2006, show a linear correlation between EA and the number of carbon atoms in PAHs. This linear correlation is consistent with the additivity of the law Van der Waals. The enthalpy of perylene desorption of soot particles produced by a diesel engine was determined by Steiner and Burtscher (1994). Zacharia et al. (2004) studied the interaction between benzene and three PAHs (naphthalene, coronene, and ovalene) with graphite using the programmed thermal desorption technique coupled with mass spectrometry. Isotherms of adsorption of benzene, ethylbenzene, naphthalene, acenaphthylene and acenaphthene on n-hexane combustion soot was measured by Aubin and Abbatt (2006).

A comparison carried out between the activation energies of desorption obtained in our study and the sublimation enthalpies of the corresponding species relating to the HAP binding energies of desorption of a multilayer coating. 
Nguyen Mai Lan/Vietnam Journal of Earth Sciences 42(2020)

Table 1. Parameter Arrhenius of $\mathrm{k}_{\mathrm{des}}$ from desorption kinetics of PAHs

\begin{tabular}{|c|c|c|c|c|}
\hline PAH & Structure & $k_{0}\left(10^{15} \mathrm{~s}^{-1}\right)^{a}$ & $E_{\mathrm{A}}^{b}\left(\mathrm{~kJ} \mathrm{~mol}^{-1}\right)$ & $\mathrm{T}(\mathrm{K})$ \\
\hline Phe & & $0.4(4)$ & $85.6 \pm 2.8$ & $250-290$ \\
\hline Ant & & $1.1(4)$ & $88.1 \pm 3.2$ & $250-290$ \\
\hline Fla & & $0.4(2)$ & $93.9 \pm 1.7$ & $260-320$ \\
\hline Pyr & & $0.6(2)$ & $95.2 \pm 1.8$ & $260-320$ \\
\hline $\mathrm{B}(\mathrm{ghi}) \mathrm{F}$ & & $7.7(2)$ & $112.1 \pm 1.9$ & $290-325$ \\
\hline Ace & & $3.5(2)$ & $107.1 \pm 1.9$ & $280-315$ \\
\hline $\mathrm{B}(\mathrm{a}) \mathrm{A}$ & & $3.5(14)$ & $113.9 \pm 6.9$ & $295-335$ \\
\hline Chry & & $5.3(5)$ & $114.9 \pm 3.9$ & $295-335$ \\
\hline $\mathrm{B}(\mathrm{e}) \mathrm{P}$ & & $3.2(4)$ & $119.9 \pm 4.1$ & $310-355$ \\
\hline $\mathrm{B}(\mathrm{b}) \mathrm{F}$ & & $3.7(4)$ & $118.7 \pm 3.5$ & $310-350$ \\
\hline $\mathrm{B}(\mathrm{k}) \mathrm{F}$ & & $3.4(6)$ & $120.8 \pm 4.9$ & $310-355$ \\
\hline $\mathrm{B}(\mathrm{a}) \mathrm{P}$ & & $3.9(5)$ & $121.8 \pm 4.4$ & $315-355$ \\
\hline B(ghi)P & & $8.4(4)$ & $129.7 \pm 4.4$ & $340-370$ \\
\hline $\mathrm{DB}(\mathrm{ah}) \mathrm{A}$ & & $10.2(4)$ & $128.0 \pm 3.9$ & $335-365$ \\
\hline IP & & $10.2(8)$ & $130.6 \pm 6.1$ & $340-370$ \\
\hline Anth & & $10.7(4)$ & $131.6 \pm 3.2$ & $340-370$ \\
\hline
\end{tabular}

The continuous line in Fig. 10 represents a simulation of our data with thirteen PAHs in Table 2 corresponding to the equation:

$$
E_{\mathrm{A}}=0.97 \times \Delta H_{\text {sub }}
$$

With a correlation coefficient $\mathrm{r}^{2}=0.99$.
The literature data measured on different carbon supports with different methods correlates well with the line simulating our experimental data, which shows a similarity of the values of $\mathrm{E}_{\mathrm{A}}$ and $\Delta \mathrm{H}_{\text {sub }}$ in the processes of desorption of PAHs from carbon supports. 
The activation energies of desorption of PAHs is similar with the corresponding sublimation enthalpies. It seems to be consistent with the similarity between the graphitic soot structure and the PAHs structure.

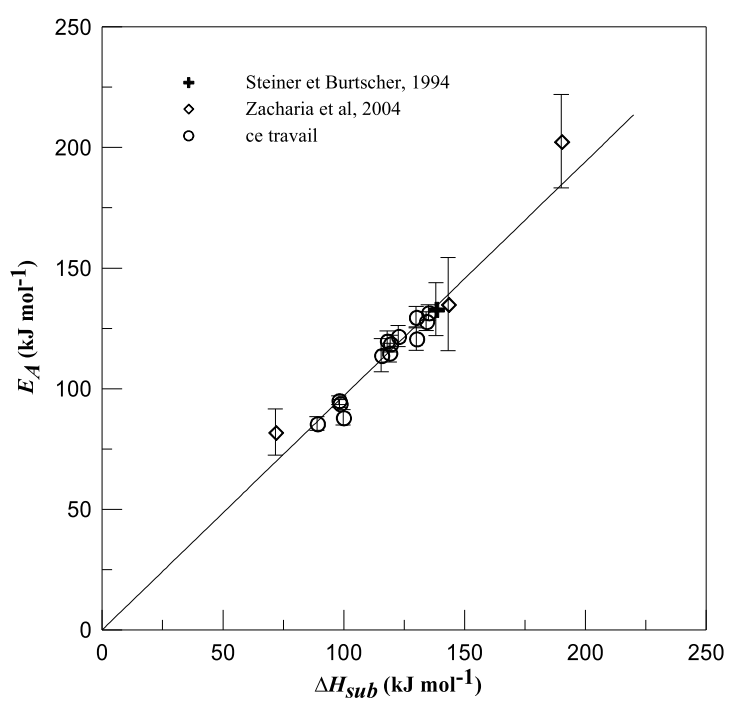

Figure 10. Linear relationship between $\mathrm{E}_{\mathrm{A}}$ and $\Delta \mathrm{H}_{\text {sub }}$ of PAHs in comparision with the literatures

Concerning the pre-exponential factors determined in this work (Table 1), we can note although the uncertainty of measurements is relatively high) the existence of a correlation: the pre-exponential factors is directly proportional to the size of the molecules of PAH. The determination of activation energies, $E_{A}$, and the preexponential factors, $\mathrm{k}_{0}$ in the majority of the desorption studies have a typical value of the order of $10^{13} \mathrm{~s}^{-1}$ while the values of literature are up to $10^{20} \mathrm{~s}^{1}$ (Rudzinski et al., 1997). Fichtorn and Miron (2002) performed theoretical calculations of the thermal desorption rate constant of a series of alkanes of a gold surface. They have shown that preexponential factors are directly proportional to the length of alkane chains and can be much higher than typical estimates for small molecules. This phenomenon exists in the adsorption and desorption of all large molecules on surfaces. Our experimental data are consistent with this conclusion for the desorption process of PAH from the soot.

Our experimental data can be applied directly to calculate the partition coefficient $(\mathrm{Kp})$ of PAHs in the atmosphere in using equation (10) (Pankow, 1987):

$$
K_{p}=\frac{N_{S} \times a_{T S P} \times T \times e^{\frac{\left(\Delta H_{d e s}-\Delta H_{\text {vap }}\right)}{R T}}}{1600 P^{\circ}{ }_{L}}
$$

for a given specific surface area $\left(\mathrm{a}_{\mathrm{TSP}}\right)$ of atmospheric aerosol and the known parameters $\left(\Delta H_{\text {vap }}, P_{L}\right)$ of the studied compounds.

Equation 10 provides a linear relationship between $\log K_{P}$ and $\log P_{L}^{0}$ to interpret the distribution of PAHs observed under the different atmospheric conditions:

$$
\log K_{p}=m_{r} \log P_{L}^{0}+b_{r}
$$

It should be noted that equation (11) applied only to a class of analogous compounds with similar values of $\left(\Delta H_{\text {des }}\right.$ $\left.\Delta H_{\text {vap }}\right)$. Comparing the measurements of Bidleman et al. (1986) and Yamasaki et al. (1982) for the gas/particle distribution of atmospheric PAHs and using $N_{\mathrm{S}}=4 \times$ $10^{-10} \mathrm{~mol} \mathrm{~cm}^{-2}$, Pankow et al. (1987) estimated a value of about $3 \mathrm{kcal} \mathrm{mol}^{-1}\left(\approx 12.5 \mathrm{~kJ} \mathrm{~mol}^{-1}\right)$ for $\left(\Delta H_{\text {des }}-\Delta H_{\text {vap }}\right)$ of the studied PAHs. The values of $\left(\Delta H_{\text {des }}-\Delta H_{\text {vap }}\right)$ obtained in our study (Table 2) for ten PAHs are in the range of 8.5 - $15.2 \mathrm{~kJ} \mathrm{~mol}^{-1}$ with an average value of (10.9 $\pm 2.5) \mathrm{kJ} \mathrm{mol}^{-1}$ (the uncertainty corresponds to a $99 \%$ confidence interval). It should be noted that six studied PAHs could not be considered for lack of existing data on their enthalpies of vaporization. Our values of $\Delta H_{\text {des }}-\Delta H_{\text {vap }}$ can be compared to the values of Yamasaki et al. (1982) $\left(8.3-16.7 \mathrm{~kJ} \mathrm{~mol}^{-1}\right)$ and Aubin and Abbatt (2006) (13-17 $\left.\mathrm{kJ} \mathrm{mol}^{-1}\right)$ for ethylbenzene and three PAHs with two aromatic rings. Our data seem to confirm that the value of $\left(\Delta H_{\text {des }}-\Delta H_{\text {vap }}\right)$ can be considered as a constant for a series of analogous molecules. 
The $\left(\Delta H_{\text {des }}-\Delta H_{\text {vap }}\right)$ is applied to calculate the fraction of the total atmospheric concentration of adsorbed PAHs on particles $(\phi)$ in using the original equation proposed by Junge (1977):

$$
\phi=\frac{c_{J} \theta_{J}}{P_{L}^{0}+c_{J} \theta_{J}}
$$

Where $\theta_{J}\left(\mathrm{~cm}^{2} \mathrm{~cm}^{-3}\right)$ represents the area of the particles and $\mathrm{c}_{\mathrm{J}}($ Torr $\mathrm{cm}$ ) a constant (for a given compound) depending on the temperature (Pankow, 1987) :

$$
c_{J}=760 R T N_{S} e^{\left(\Delta H_{d e s}-\Delta H_{v a p}\right) / R T}
$$

Table 2. Comparison of the desorption enthalpies determined in this study with the enthalpies of sublimation and vaporization of the literatures

\begin{tabular}{|l|c|c|c|c|}
\hline \multicolumn{1}{|c|}{$\mathrm{HAP}$} & ${ }^{a} \Delta H_{\text {des }}\left(\mathrm{kJ} \mathrm{mol}^{-1}\right)$ & ${ }^{b} \Delta H_{\text {sub }}\left(\mathrm{kJ} \mathrm{mol}^{-1}\right)$ & ${ }^{c} \Delta H_{\text {vap }}\left(\mathrm{kJ} \mathrm{mol}^{-1}\right)$ & $\Delta H_{\text {des }}-\Delta H_{\text {vap }}\left(\mathrm{kJ} \mathrm{mol}^{-1}\right)$ \\
\hline Phénanthrène & 85.6 & 88.9 & 76.2 & 9.4 \\
\hline Anthracène & 88.1 & 99.7 & 76.6 & 11.5 \\
\hline Fluoranthène & 93.9 & 98.3 & 85.4 & 8.5 \\
\hline Pyrène & 95.2 & 97.9 & 86.7 & 8.5 \\
\hline Benzo(a)anthracène & 113.9 & 115.5 & 99.2 & 14.7 \\
\hline Chrysène & 114.9 & 118.8 & 99.7 & 15.2 \\
\hline Benzo(e)pyrène & 119.9 & 117.9 & 110.5 & 9.4 \\
\hline Benzo(b)fluoranthène & 118.7 & 119.2 & 109.2 & 11.6 \\
\hline Benzo(k)fluoranthène & 120.8 & 130.0 & 109.2 & 10.9 \\
\hline Benzo(a)pyrène & 121.8 & 122.5 & 110.9 & \\
\hline Benzo(ghi)pérylène & 129.7 & 129.9 & ${ }^{d}$ nd & \\
\hline Dibenz(ah)anthracène & 128.0 & 134.1 & nd & \\
\hline Anthanthrène & 131.6 & 135.0 & nd & \\
\hline
\end{tabular}

${ }^{a}$ This study: $\Delta \mathrm{H}_{\mathrm{des}}=\mathrm{E}_{\mathrm{A}}$;

${ }^{b}$ Nass et al. (1995), except B(k)F (Shiu et al., 2000) and Anthanthrène (Inokuchi et al., 1952)

'Yamasaki et al. (1984);

${ }^{d}$ n.d.: not determined in the litteratures

Figure 11 shows the results of calculations with $\theta_{\mathrm{j}}=1.1 \times 10^{-5} \mathrm{~cm}^{2} \mathrm{~cm}^{-3}$ (urban conditions) (Bidleman and Harner, 2000) for $\left(\Delta \mathrm{H}_{\text {des }}-\Delta \mathrm{H}_{\text {vap }}\right)=10.9 \pm 2.5 \mathrm{~kJ} \mathrm{~mol}^{-1}$ (this study) and $12.5 \mathrm{~kJ} \mathrm{~mol}^{-1}$ (Pankow, 1987). It is found that (1) the calculated value of PAHs in the particulate phase for the most and least volatile compounds are insensitive to the value of $\left(\Delta \mathrm{H}_{\text {des }}-\Delta \mathrm{H}_{\text {vap }}\right)$; (2) this value is most sensitive to $\left(\Delta \mathrm{H}_{\text {des }}-\Delta \mathrm{H}_{\text {vap }}\right)$ for moderately volatile molecules (phenanthrene to benzo(k)fluoranthene). This emphasizes the importance of using appropriate values of $\left(\Delta \mathrm{H}_{\text {des }}-\Delta \mathrm{H}_{\mathrm{vap}}\right)$ to correctly simulate the distribution of semi-volatile species and this also shows the importance of $\Delta H_{\text {des }}$ measurements performed in this work which seems to be the first to be achieved with controlled soot samples and for a wide range of analogous compounds.

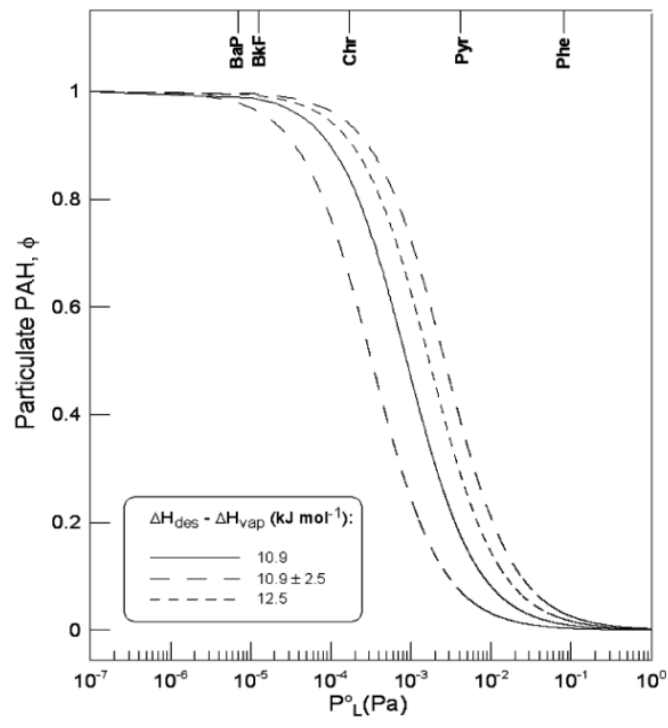

Figure 11. Variation of $\phi$ in function of $\mathrm{P}^{0}{ }_{\mathrm{L}}$ according to the Junge equation in urban condition $\left(\theta_{\mathrm{j}}=1.1 \times 10^{-5} \mathrm{~cm}^{2} \mathrm{~cm}^{-3}\right)$ for different values of $\left(\Delta \mathrm{H}_{\text {des }}-\Delta \mathrm{H}_{\mathrm{vap}}\right)$ 


\section{Conclusions}

During this work, we studied adsorption/desorption processes of PAHs on soot particles that are by-products of incomplete combustion in aircraft emissions. They contain high levels of PAHs and are a very important source of these compounds in the atmosphere. In the laboratory, these soot particles were generated on a flat-flame burner premixed with a representative mixture of kerosene (74\% decane, $15 \%$ propylbenzene, and $11 \%$ propylcyclohexane).

The desorption of adsorbed PAHs on soot was studied in a low pressure flow reactor with monitoring of species concentrations in the gas phase by mass spectrometry and those of particulate PAHs by liquid chromatography with fluorescence detection and absorption in the gas phase. UV-Vis (off-line analysis after prior extraction of PAHs). For the extraction of PAHs from soot particles we used the method of extraction by Ultrasound Probe whose following parameters were optimized: nature of the solvent, extraction time and soot mass/extraction solvent volume ratio.

The soot samples being introduced into the reactor, the kinetic measurements consist in following the adsorbed PAH concentrations on the soot surface as a function of the time of desorption (absence of oxidant) or reaction (presence of oxidant) corresponding to the time of residence in the reactor.

The desorption rates of PAHs were measured as a function of temperature for each PAH identified in the soot. This allowed us to calculate the desorption activation energies $\left(\mathrm{E}_{\mathrm{A}}\right)$ as well as the pre-exponential factors $\left(\mathrm{k}_{0}\right)$ from the established Arrhenius equation for each identified PAH. The experimental data obtained in this work correlate well with the theoretical data of the literature concerning the increase of $\mathrm{k}_{0}$ with the number of aromatic rings of PAHs. These experiments also made it possible to demonstrate a similarity between the activation energy values $\left(\mathrm{E}_{\mathrm{A}}\right)$ and the sublimation enthalpies $\left(\Delta \mathrm{H}_{\text {sub }}\right)$ in the desorption processes of PAHs from carbon supports. The observation of a plateau in $\mathrm{PAH}$ desorption kinetics shows that some PAHs do not desorb on the timescale of the experiments $\left(\begin{array}{ll}\sim 00 & \mathrm{~min}\end{array}\right)$. Experiments suggest partial entrapment of PAHs in microporous soot structure.

The experimental data obtained in this study were applied directly to calculations of the distribution of PAHs in the atmosphere using theoretical models. Indeed, the values of the desorption activation energies measured for each PAH in this study make it possible to calculate the distribution constants $\mathrm{K}_{\mathrm{p}}$ for each compound. We have confirmed the hypothesis that the value $\left(\Delta \mathrm{H}_{\text {des }}-\Delta \mathrm{H}_{\text {vap }}\right)$ used in the theoretical approaches to calculate $\mathrm{K}_{\mathrm{p}}$ can be considered constant for a series of analogous compounds, such as PAHs in this study. On the other hand, the value of the $\mathrm{PAH}$ distribution coefficient is sensitive to this value. This shows the importance of $\Delta \mathrm{H}_{\text {des }}$ measurements performed in this work in order to reduce the uncertainties in simulations of PAH distribution in the atmosphere.

\section{References}

Aubin D.G., Abbatt J.P., 2006. Laboratory Measurements of Thermodynamics of Adsorption of Small Aromatic Gases to n-Hexane Soot Surfaces. Environ. Sci. Technol., 40, 179-187.

Aviation Benefits beyond borders, 2018. https://aviationbenefits.org/.

Bidleman T.F., Billings W.N., Foreman W.T., 1986. Vapor-particle partitioning of semivolatile organic compounds: estimates from field collections. Environ. Sci. Technol., 20, 1038-1043.

Bidleman T.F., Harner T., 2000. Sorption of persistent organic pollutants to aerosols. Estimating chemical properties for the environmental and health sciences, 233-260.

Cong Liu, Shanshan Shi, Charles Weschler, Bin Zhao, Yinping Zhang, 2013. Analysis of the Dynamic 
Interaction Between SVOCs and Airborne Particles, Aerosol Science and Technology, 47, 125-136.

Fichthorn K.A., Miron R.A., 2002. Thermal Desorption of large molecules from solid surfaces. Phys. Rev. Lett., 89, 196103-196107.

Inokuchi T., Shiba S., Handa T., Akamatsu H., 1952. Heats of sublimation of condensed Polynuclear Aromatic Hydrocarbons. Bull. Chem. Soc. Jpn., 25, 299-302.

Junge C.E., 1977. Basic considerations about trace constituents in the atmosphere as related to the fate of global pollutants. In "Fate of pollutants in the air and water environments". Edited by I.H. Suffet. John Wiley, New York, 7-26.

Lelie'vre S., Bedjanian Y., Laverdet G., Le Bras G., 2004. Heterogeneous reaction of $\mathrm{NO}_{2}$ with hydrocarbon flame soot. Journal of Physical Chemistry A, 108, 10807.

Lelièvre S., Bedjanian Y., Pouvesle N., Delfau J.L., Vovelle C., Le Bras G., 2004. Heterogeneous reaction of ozone with hydrocarbon flame soot. Physical Chemistry Chemical Physics, 6, 1181.

Meng Lia, Fengxia Baoa, Yue Zhanga, Wenjing Song, Chuncheng Chena, Jincai Zhaoa, 2018. Role of elemental carbon in the photochemical aging of soot. PNAS, 115(30), 7717-7722.

Nass D., Lenoir D., Kettrup A., 1995. Calculation of the Thermodynamic Properties of Polycyclic Aromatic Hydrocarbons by an Incremental Procedure. Angew. Chem. Int. Ed. Engl., 34, 1735-1736.

Pankow J.F., 1987. Review and comparative analysis of the theories on partitioning between the gas an aerosol particulate phase in the atmosphere. Atmos. Environ., 21, 2275-2283.

Rudzinski W., Borowiecki T., Dominko A., Panczyk T., 1997. New method of estimating the solid surface energetic heterogeneity from TPD spectra based on the statistical rate theory of interfacialt ransport. Langmuir, 13, 3445-3453.

Shiu W.-Y., Ma K.-C., 2000. Temperature Dependence of Physical - Chemical Properties of Selected Chemicals of Environmental Interest. I. Mononuclear and Polynuclear Aromatic Hydrocarbons. J. Phys. Chem. Ref. Data, 29(1), 41-130.

Steiner D., Burtscher H.K., 1994. Desorption of perylene from combustion, $\mathrm{NaCl}$ and Carbon particles. Environ. Sci. Technol., 28, 1254-1259.

Yamasaki H., Kazuhiro K., Hiroko M., 1982. Effects of ambient temperature on aspects of airborne Polycyclic aromatic Hydrocarbons. Environ. Sci. Technol., 16(4), 189-194.

Yamasaki H., Kuwata K., Kuge Y., 1984. Determination of Vapor Pressure of Polycyclic Aromatic Hydrocarbons in the Supercooled Liquid Phase and their Adsorption on Airborne Particulate Matter. Nippon Kagaku Kaish, 8, 1324-1329.

Yuri Bedjanian, Stéphane Lelièvre, Georges Le Bras, 2005. Experimental study of the interaction of $\mathrm{HO}_{2}$ radicals with soot surface. Physical Chemistry Chemical Physics, 7, 334-341.

Zacharia R., Ulbricht H., Hertel T., 2004. Interlayer cohesive energy of graphite from thermal desorption of polyaromatic hydrocarbons. Phys. Rev., B., 69, 155406-155412. 